\title{
Carcinoma de células escamosas y patología molecular
}

\section{Squamous cell carcinoma and molecular pathology}

Luz Fernanda Sua, MD., PhD. (1); Liliana Fernández, MD. ${ }^{(2)}$

(1)Anatomía Patológica y Patología Clínica, Departamento de Patología y Medicina de Laboratorio, Patología pulmonar. Ciencias Biomédicas. Línea de investigación Biomédica en Tórax, Fundación Valle del Lili. Profesora Clínica Auxiliar, Facultad de Ciencias de la Salud, Universidad Icesi. Cali, Colombia.

${ }^{(2)}$ Medicina Interna, Neumología y Neumología intervencionista. Línea de Investigación Biomédica en Tórax. Fundación Valle del Lili. Profesora Clínica Asociada, Facultad de Ciencias de la Salud, Universidad Icesi. Cali, Colombia.

Correspondencia: Luz Fernanda Sua, correos electrónicos: lufer24@hotmail.com, 1fsua@fcvl.org

Recibido: 10/09/16. Aceptado: 28/09/16.

\section{Terminología}

Carcinoma de células escamosas.

\section{Definición}

Se trata de una malignidad primaria pulmonar que evidencia usualmente metaplasia escamosa como lesión preinvasiva la cual progresa a displasia, carcinoma in situ y carcinoma invasivo. Tiene una asociación muy fuerte con el tabaquismo: más del $50 \%$ de los tumores de este tipo aparecen en fumadores y están relacionados directamente con el número de cigarrillos/año. Por consiguiente, dejar de fumar es la medida más eficaz para reducir el riesgo de cáncer de células escamosas en el mundo.

\section{Características clínicas}

El riesgo incrementa con la edad, siendo más frecuente en mayores de 70 años; el tabaco tiene alta asociación con la incidencia de este tumor en hombres, en especial de la etnia afroamericana. Se puede encontrar en pacientes asintomáticos entre el 7 al 10\% de los casos, usualmente como hallazgo incidental en estudios rutinarios de imágenes. Los signos y síntomas más frecuentes son tos, hemoptisis y disnea; adicionalmente se puede asociar a los síndromes de Pancoast o de Horner, o a hipercalcemia paraneoplásica. Se debe considerar carcinoma de células escamosas en fumadores con masas de presentación central y/o atelectasia postobstructiva con o sin neumonía.

\section{Diagnóstico diferencial}

- Adenocarcinoma

- Carcinoma de células pequeñas

- Metástasis mediastinales de otro tumor primario

- Tumores carcinoides

\section{Diagnóstico}

Es posible obtener muestras para estudio citológico de esputo en las cuales se pueden identificar células malignas, broncoscopia con un $40 \%$ de falsos negativos en el diagnóstico a pesar de lesiones endobronquiales y tumores centrales, cepillado de la mucosa bronquial y biopsias guiadas por imagen.

\section{Patología}

\section{Macroscópica}

Lesión endobronquial irregular, a veces de aspecto polipoide, con invasión de la pared bronquial, obstrucción endobronquial total o parcial y con compromiso frecuente de ganglios linfáticos. Un número considerable de tumores de células 
escamosas se presenta con lesiones cavitadas de gran tamaño.

\section{Microscópica}

Células grandes con núcleos irregulares, nucléolos grandes, puentes intercelulares, perlas de queratina, eosinófilos, mitosis y necrosis tumoral (figura 1).

\section{Patología molecular}

\section{Inmunohistoquímica}

Tumores positivos para la proteína del gen p40 nuclear que demuestra su origen primario pulmonar (figura 2), además del gen p63 nuclear y en los citoplasmas para la citoqueratina $5 / 6$ que confirma su origen en el epitelio escamoso (figura 3).

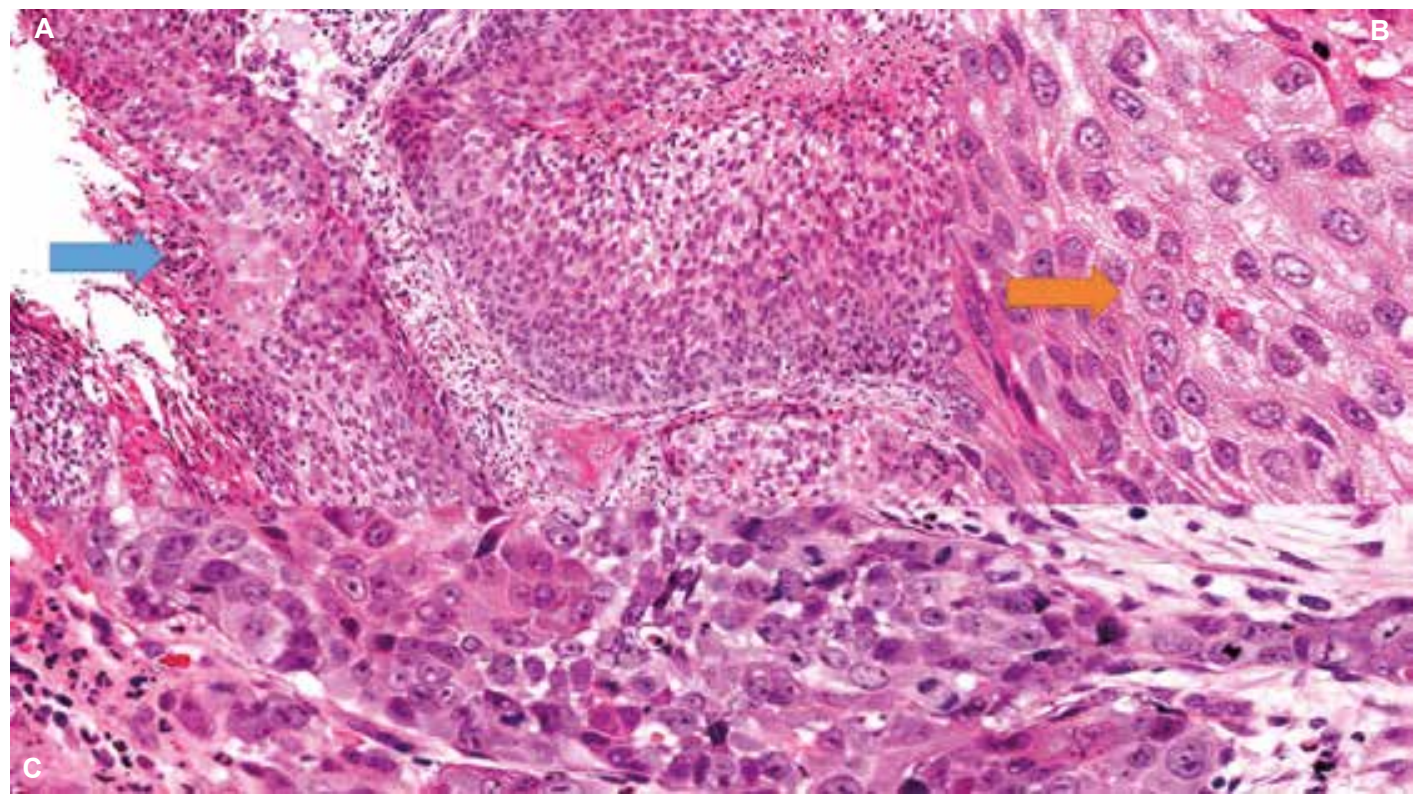

Figura 1. (A) Metaplasia y displasia de alto grado (flecha azul) con presencia de tumor de células escamosas infiltrante. (B) Células escamosas tumorales y puentes intercelulares (flecha naranja) característicos de este tipo tumoral. (C) Pleomorfismo celular y mitosis. Coloración H\&E.

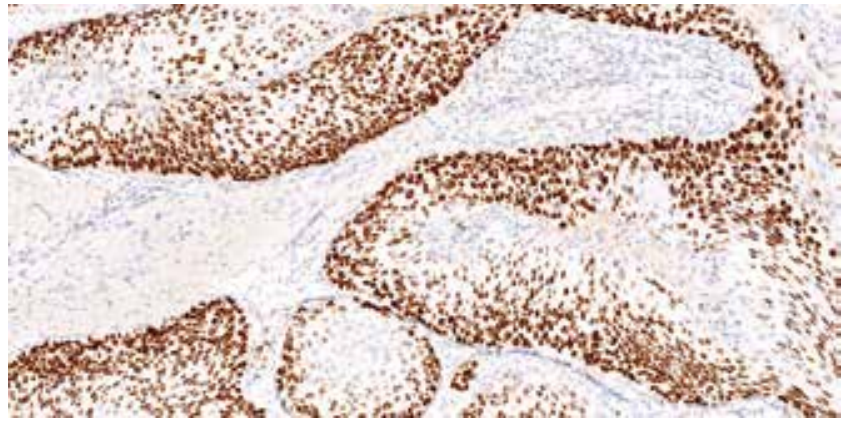

Figura 2. Técnica de inmunohistoquímica: expresión proteica del gen p40 nuclear que demuestra el origen primario pulmonar.

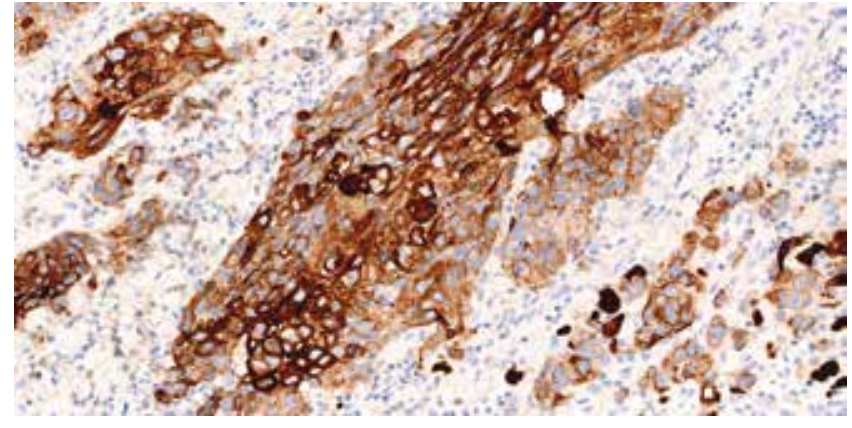

Figura 3. Técnica de inmunohistoquímica: expresión proteica de la citoqueratina 5/6 citoplasmática vista en las células de línea escamosa. 
Son negativos para el gen TTF-1 nuclear y Napsina A citoplasmático.

\section{Estudios de la mutación del gen EGFR (exones 18, 19, 20 y 21) y rearreglos del gen EML4-ALK}

En los tumores de células escamosas no están indicados los estudios de la mutación del gen EGFR ni los rearreglos del gen EML4-ALK, a menos que se den en individuos jóvenes no fumadores en quienes además se pueden realizar estudios del PDL1 (programmed death-ligand 1) para identificar candidatos a inmunoterapia (actualmente en ensayos clínicos en Colombia).

\section{Bibliografía}

1. Kataoka K, Osaka E, Shimizu T, Okamura Y, Yoshida Y, Tokuhashi Y. Lung squamous cell carcinoma with brachial soft tissue metastasis responsive to gefitinib: Report of a rare case. Thoracic Cancer. 2016;7:676-80. doi: 10.1111/17597714.12366.

2. Fernández L, Sua L, Rodríguez L, Muñoz C, Velásquez M, Restrepo J. Epidermal growth factor receptor mutation in patients with non-small cell lung carcinoma in Fundación Valle del Lili, a universitary hospital of reference in Latin America. Am J Respir Crit Care Med.2016;193:A2598. 